\title{
Corelation of Sehgal Index and Rbc Indices For Screening of Beta Thalassemia Trait
}

\author{
Authors \\ Ujwala Maheshwari ${ }^{1}$, Amruta Padhye ${ }^{2}$, Parineeta Samant $^{3}$, Reeta Dhar ${ }^{4}$ \\ ${ }^{1}$ Professor, Department of Pathology, MGM Medical College, Kamothe, Navi Mumbai \\ ${ }^{2}$ PG student, Department of Pathology, MGM Medical College, Kamothe, Navi Mumbai \\ ${ }^{3}$ Professor, Department of Biochemistry, MGM Medical College, Kamothe, Navi Mumbai \\ ${ }^{4}$ Head of Department, Department of Pathology, MGM Medical College, Kamothe, Navi Mumbai
}

\begin{abstract}
Background: Hemoglobinopathies are a group of disorders of hemoglobin synthesis characterized by the absence or reduction of one or more of the globin chains of hemoglobin.

Materials and Methods: This is an observational study conducted at the department of Pathology at MGM Hospital, Navi Mumbai. A total number of 72 samples were obtained and run on HPLC (BIORAD D10) over a period of 6 months from January 2016 - June 2016.

Objectives: To evaluate the Sehgal index and compare it to the CBC based indices for best combination of sensitivity and specificity for the prediction of beta thalassemia trait.

Result and Conclusion: In our study, the percentage of beta thalassemia trait in the study group was 20.83.

Keywords: sehgal index, beta thalassemia trait, rbc indices.
\end{abstract}

\section{Introduction}

The thalassemias are inherited group of disorders of hemoglobin synthesis characterized by the absence or reduction in output of one or more of the globin chains of hemoglobin. ${ }^{(1)}$ The structural variants result from substitution of one or more amino acids in the globin chains of the hemoglobin molecule. They have an autosomal recessive inheritance and majority of beta thalassemias are caused by point mutations. Most common causes of microcytic hypochromic anemia are iron deficiency anemia and beta thalassemia trait. ${ }^{(2)}$ In Iron deficiency anemia (IDA), iron therapy is the mainstay of treatment. And there has been no proven role of genetic counselling. Whereas in Beta thalassemia trait (BTT), iron therapy contraindicated and the condition can be prevented by genetic counselling of the parents. ${ }^{(2)}$

\section{Materials and Methods}

This observational retrospective study was conducted in the department of pathology of a tertiary hospital. All patient samples which were sent to the central hematology laboratory for suspected hemoglobinopathies from the period of January 2016 - June 2016 were included. The total number of samples was 72 and the age group of patients was 1 to 72 years. Patients' samples were run on HPLC (BIORAD- D10) based on high $\mathrm{Hb}$ A2 levels (>3.5) and CBC was run on Sysmex KX 21 analyzer for all HPLC samples. Our aim was to evaluate the Sehgal index and compare it to the 
CBC based indices for best combination of sensitivity and specificity for the prediction of beta thalassemia trait. All data with mean corpuscular volume $(\mathrm{MCV})$ of $>110 \mathrm{fl}$, patients with history of blood transfusion and those patients who do not consent were excluded from the study. This study was proceded after the approval from the Institutional Ethics Committee.

\section{Results and Observation}

We evaluated 72 cases of which 16 were males and 56 were females in a period of 6 months. Out of these cases 15 were found to have Beta thalassemia trait having $\mathrm{Hb} \mathrm{A} 2$ variation and the remaining were either normal or had iron deficiency anaemia. The percentage of Beta thalassemia trait in the study group was $20.83 \%$.

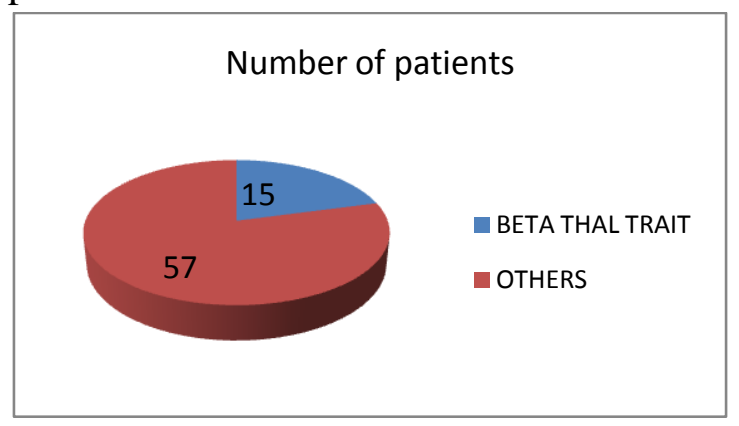

The list of various discriminant factors (CBC based indices) used in the study are:

1. Mentzer index $\mathrm{MCV} / \mathrm{RBC}$

2. Sehgal index MCVxMCV/RBC

For Sehgal index, the cut off was 972 and Mentzer index was $<14$ for beta thalassemia trait.

Table 1:

\begin{tabular}{|l|c|c|c|}
\hline & $\begin{array}{c}\text { Sehgal Index } \\
<972\end{array}$ & Sehgal index $>972$ & Total \\
\hline Beta Thal Trait & 13 & 2 & 15 \\
\hline Non Beta Thal & 6 & 51 & 57 \\
\hline Total & 19 & 53 & 72 \\
\hline
\end{tabular}

Sehgal index $<972$ has a sensitivity of $86.6 \%$ and a specificity of $89.4 \%$ to predict beta thalassemia trait similar to the study conducted by Sehgal et al. ${ }^{(2)}$ and Trivedi DP et al. ${ }^{(4)}$

Table 2:

\begin{tabular}{|l|c|c|c|}
\hline & $\begin{array}{c}\text { Mentzer Index } \\
<14\end{array}$ & $\begin{array}{c}\text { Mentzer } \\
\text { Index }>14\end{array}$ & Total \\
\hline Beta Thal Trait & 11 & 4 & 15 \\
\hline Non Beta Thal & 5 & 52 & 57 \\
\hline Total & 16 & 57 & 72 \\
\hline
\end{tabular}

Mentzer index $<14$ has a sensitivity of $73.3 \%$ and a specificity of $91.22 \%$ to predict beta thalassemia trait which was similar to the study conducted by Sehgal et al ${ }^{(2)}$, Rathod DA et $a l .{ }^{(3)}$ and Trivedi DP et al. ${ }^{(4)}$

\section{Discussion}

In our country, Iron deficiency anaemia and Beta thalassemia trait are common causes of microcytic hypochromic blood picture. ${ }^{(2)}$ Non diagnosis and misdiagnosis of carriers of thalassemia trait can result in a potential homozygous offspring. For reducing the morbidity and mortality of beta thalassemia, appropriate screening, detection of patients and counselling of couples at risk are the most important measures. A discriminant formula or CBC based indices with a combination of high sensitivity and specificity for detecting BTT would be a very useful economic tool in the investigation of microcytic hypochromic anemia to rule out beta thalassemia trait. So, before subjecting the patients for HPLC, Sehgal index with a cut off 972 and Mentzer index with a cut off of 14, are useful screening tests.

\section{References}

1. R.B. Colah et al. HPLC Studies in Hemoglobinopathies. Indian Journal of paediatrics Volume 74- July 2007

2. Sehgal et al. Sehgal index: A new index and its comparison with other complete blood count-based indices for screening of beta thalassemia trait in a tertiary care hospital. Indian J Pathol Microbiol 2015;58:310-5

3. Rathod DA et al. Usefulness of cell counterbased parameters and formulas in detection of beta-thalassemia trait in areas of high prevalence. Am J Clin Pathol 2007;128:5859.

4. Trivedi DP et al. Discriminant functions in distinguishing beta thalassemia trait and Iron deficiency anemia: The value of the RDWSD. Internet J Hematol 2010;7. 